\section{The Legionella Plan}

Although most cases of Legionnaires' disease occur in isolation, recent outbreaks of the disease, including one associated with the Melbourne Aquarium, have attracted international media attention. Minimising the risk of an outbreak of Legionnaires' disease has been a key priority leading up to and during the Games, because large numbers of people will congregate in areas of the city where water cooling systems with cooling towers are located.

Implementation of the Legionella Plan depends on partnerships between public health unit Olympic Coordinators and environmental health officers from local government across metropolitan Sydney. Local government is responsible for maintaining registers of cooling towers. Councils have expanded their inspection regimen of cooling towers and there are specific local plans in preparation for the Games.

Strategies in place to maximise compliance with the cleaning and maintenance provisions for cooling towers, outlined in the NSW Public Health Act 1991, include:

- maintenance of a Geographical Information System (GIS) database of all cooling towers registered with local councils

- registration of all buildings owned by the Commonwealth government with the relevant local council

- review of the Legionella Emergency Management Plan

- inspection of cooling towers in areas of potential risk

- provision of educational material on best management to building owners and operators.

\section{ENVIRONMENTAL HEALTH SERVICES IN OLYMPIC VENUES}

The NSW Department of Health will provide an environmental health presence within Olympic and
Paralympic venues. The key tasks involved are outlined in Environmental Health Standing Procedures for Olympic Venues.

A pre-inspection of each venue will be carried out prior to sporting events commencing. This will involve final inspections of all water cooling systems and checks on provision of adequate waste services within medical centres, provision of sanitation and general safety matters. Routine inspections of waste and sanitation services will be carried out at intervals during the Games.

\section{After the Games}

The Games have provided an excellent opportunity to build environmental health awareness in many sectorsparticularly shipping and building maintenance. Improved liaison between local councils and the NSW Health system will yield ongoing benefits. For the first time, large numbers of environmental health officers from the public health network and local councils are working closely together. The result will be a better understanding of respective roles and responsibilities, and a lasting legacy of networks and associations.

\section{ACKNOWLEDGEMENTS}

I would like to acknowledge the support and leading role played by the public health units, local councils and the Olympic Environmental Health Steering Committee in the development and implementation of this plan.

\section{REFERENCE}

1. Maria Visotina. Health and Medical Services for the Centennial Olympic Games Atlanta Georgia. Internal Report. Sydney: NSW Department of Health, 1996.

\title{
INTRODUCING A NSW VESSEL INSPECTION PROGRAM FOR CRUISE SHIPS
}

Karen Banwell and Tony Butler

Olympic Planning Unit

NSW Department of Health

Mark Ferson, Steve Hatzi and Paul Paraskevopoulos South Eastern Sydney Public Health Unit

This article outlines the background to the introduction of a Vessel Inspection Program in NSW. The program aims to ensure the health and safety of passengers and crew on cruise ships through a hygiene inspection regimen.
During the Sydney 2000 Olympic and Paralympic Games, nine cruise ships and two tall ships will be moored in Sydney Harbour for just over three weeks. Eight ships will serve as floating hotels for Olympic sponsors and their guests, and one will serve as accommodation for international broadcasting personnel. The floating hotels will provide approximately 6,000 beds at any one time with an overall throughput of around 32,000 people. The average length of stay is expected to be three to four days.

Outbreaks of disease on cruise ships are well documented. ${ }^{1-3}$ Gastroenteritis, Legionnaires' disease, 
influenza and tuberculosis have all been reported. ${ }^{4}$ The potential for outbreaks of disease to affect a large number of individuals arises from the closed environment aboard ships that can promote the spread of infection. Because large numbers of people gather in confined spaces the person-to-person transmission rate is probably higher than for land-based accommodation. Disease can also be introduced from taking on board contaminated water and food supplies, unhygienic work practices, and poorly maintained swimming or spa pools and ventilation systems.

When specific infectious diseases are identified on board a vessel that has arrived in Australia from international waters, they are reported to the Australian Quarantine Inspection Service via the Pratique or human health clearance paper, as defined in the Quarantine Act 1908. Reporting of cases of disease between Commonwealth and NSW Government agencies is informal. The NSW Ombudsman identified a lack of a clear and coordinated reporting system of disease to the NSW Department of Health following an outbreak of probable viral gastroenteritis on board a Sydney-based cruise vessel in 1996. The NSW Vessel Inspection Program was developed in response.

Within the cruise shipping industry there is also believed to be substantial under-reporting of illness by passengers. As little as 25 per cent of passengers with diarrhoea have been found to present to the ship's doctor. ${ }^{1}$ Under the NSW Public Health Act 1991 medical practitioners are obliged to report outbreaks of gastroenteritis in institutions (which might conceivably include cruise ships) and clusters of food poisoning in two or more associated cases. Respiratory illness is not notifiable, except for the requirement for hospitals to report cases of suspected Legionnaires' disease.

Since 1992, officers of the South Eastern Sydney Public Health Unit (SESPHU) have investigated health complaints on ships visiting the Port of Sydney, which falls within the jurisdiction of the South Eastern Sydney Area Health Service. However, the large number of ships coming to Sydney for the 2000 Olympic and Paralympic Games demanded that a more formal process be developed to ensure the health and safety of passengers and crew, particularly as ships are not usually moored for such extended periods.

\section{THE NSW VESSEL INSPECTION PROGRAM}

The NSW Vessel Inspection Program (VIP) was developed to provide cruise ship owners with suitable guidance about NSW legislation. The NSW Food Act 1989 and the NSW Public Health Act 1991 have provisions that allow for the inspection of cruise ships and the collection of information on illness. The VIP represents a collaborative effort between the cruise ship industry, the NSW Department of Health and SESPHU and builds on the informal inspection system that exists between the SESPHU and the local cruise ship industry.
Cruise ships sail through a range of international jurisdictions, so it is important that any new program is consistent with existing programs. The VIP is closely modelled on the United States Public Health Service Vessel Sanitation Program (US VSP) conducted by the Centres for Disease Control and Prevention (CDC), based in Atlanta, Georgia. This program has been successful in reducing diarrhoeal illness on board cruise ships since its introduction in $1975 .^{3}$

\section{Aims of the Vessel Inspection Program}

The aims of the VIP are to identify and minimise contaminated food or water and unhygienic work practices or conditions that may contribute to the introduction, transmission or spread of communicable diseases on cruise ships. Inspections are carried out on the water supply, food preparation and bar areas and any other area where food is prepared and served. The general cleanliness and management of food storage areas, ventilation, swimming pools, spa pools and auxiliary services such as child care and hairdressing are also investigated. Each ship is assigned a score out of 100 based on the above criteria. Scores of less than 85 are flagged as unsatisfactory. ${ }^{3}$ In extreme cases, a recommendation 'not to sail' can be served by the NSW Chief Health Officer until all risks to health have been rectified.

\section{Olympic Games Schedule}

A NSW Health team has undergone training using the VIP and will carry out full inspections on each ship that will be berthed in Sydney during the Games. Depending on the result of the inspection and the food services that will be provided, follow up inspections will be carried out based on an assessment of risk for the time the ships are berthed in Sydney. Because the provision of potable water and wastewater services to the ships will be land-based, special attention will be given to the connection and supply of these services.

\section{Future challenges for the Vessel Inspection Program}

The United States cruise shipping market presently has 280 ships sailing mainly out of Miami, but also Los Angeles, Seattle and Houston. The cruise shipping market in Asia is also growing fast. In keeping with the demand, shipping companies are upgrading and constructing new ships with some currently being built similar to the super liners of the past and catering for up to 2500 passengers and 1500 crew. The experience of the 2000 Olympic and Paralympic Games will leave the NSW VIP well prepared for the challenges posed if any such ships make their way to Sydney.

\section{ACKNOWLEDGEMENTS}

We would like to acknowledge the assistance of Captain Dan Harper and Lieutenant Commander Jon Schnoor from the United States Centers for Disease Control and Prevention, and members of the Healthy Cruise Working Group, for their help in the development of this program. 


\section{REFERENCES}

1. Danneberg AL, Yashuk JC, Feldman RA. Gastrointestinal illness on passenger cruise ships 1975-1978. Aust J Public Health 1982; 72: 484-488.

2. Addis DG, Yashuk JC, Clapp De, Blake PA. Outbreaks of diarrhoeal illness on passenger cruise ships, 1975-85. Epidem. Infect 1989; 103: 63-72.
3. US Public Health Service. Vessel sanitation program operations manual. Atlanta, Georgia: US Department of Health and Human Services, 1987.

4. Ferson M, Paraskevopoulos P, Hatzi S, Yankos P, Fennell $\mathrm{M}$, Condylios A. Summer influenza A outbreak on a transTasman cruise. Commun Dis Intell 2000; 24:45-47.

\section{HEALTH SURVEILLANCE ON CRUISE SHIPS DURING THE SYDNEY 2000 OLYMPIC AND PARALYMPIC GAMES}

Peter Waples, Sarah Thackway and Karen Banwell

Olympic Planning Unit

NSW Department of Health

Mark Ferson and Steve Hatzi

South Eastern Sydney Public Health Unit

During the Sydney 2000 Olympic and Paralympic Games, nine cruise ships will be berthed in Sydney Harbour, acting

\section{FIGURE 5}

\section{CRUISE SHIP HEALTH SURVEILLANCE}

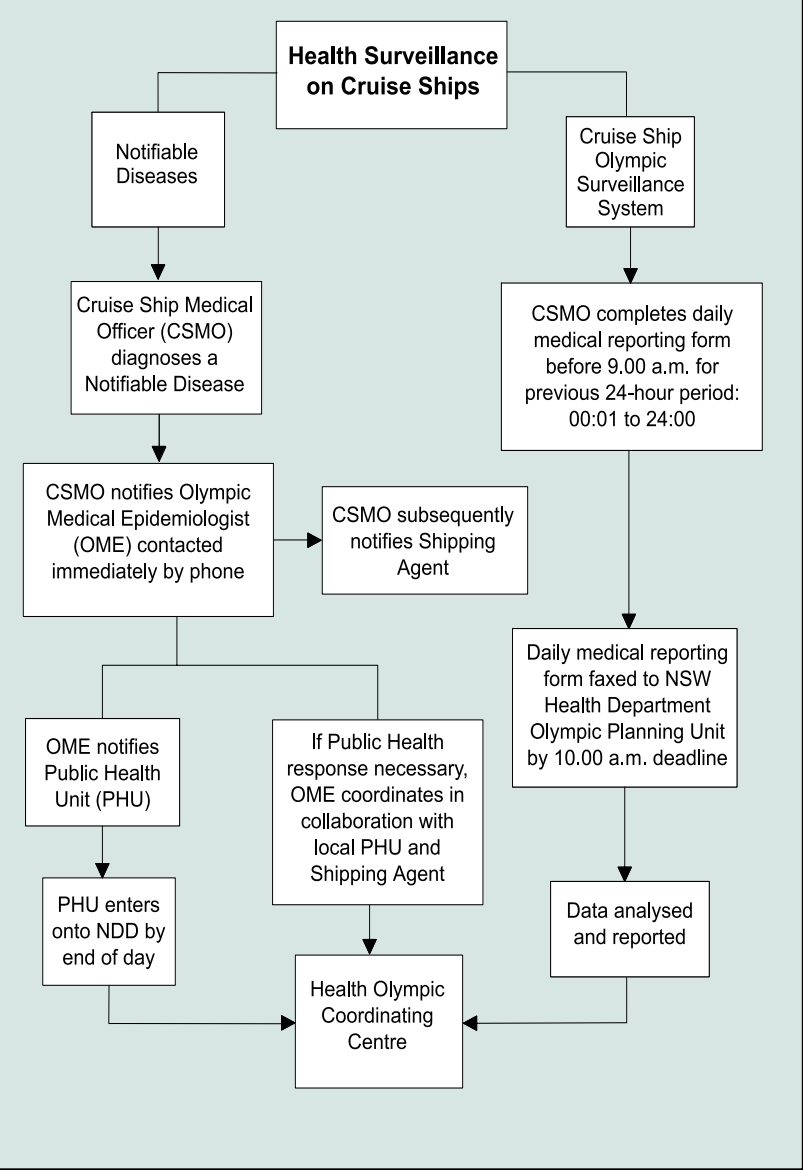

as floating hotels for an estimated 32,000 guests. Outbreaks of disease including gastroenteritis, Legionnaire's disease, influenza, and tuberculosis (TB) are well documented aboard cruise ships, ${ }^{1-7}$ and the closed environment aboard the ships may promote the occurrence of outbreaks of disease that can affect large numbers of individuals. During the Games, there is also a potential for outbreaks of disease to occur from sources outside cruise ships but affecting ships' passengers.

This article describes the plans for health surveillance on cruise ships during the Games, which will be an important component of the larger Olympic Health Surveillance System (OHSS). The overall OHSS is described in the article by Thackway on page 142, while the NSW Vessel Inspection Program, a hygienic inspection regimen for cruise ships, is described in the article by Banwell and Butler et al. (page 148).

\section{HEALTH SURVEILLANCE ON CRUISE SHIPS DURING THE GAMES}

During the Games, health surveillance on cruise ships will have two reporting streams (see Figure 5):

- Notifiable Disease Reporting (NDR)

- Cruise Ship Olympic Surveillance System (CSOSS).

\section{Notifiable Disease Reporting}

During the Games period, all cruise ships will be required to comply with the NSW Public Health Act and Regulations (1991), and notify the NSW Department of Health of:

- outbreaks of gastroenteritis

- two or more linked cases of food poisoning

- other notifiable diseases.

Cruise Ship Medical Officers will report any notifiable diseases, unusual disease clusters or public health-related problems to the Olympic Medical Epidemiologist (see article by Banwell and Butler et al. on page 148). The Medical Epidemiologist will then advise the appropriate public health agency (see Figure 5). 